\title{
CONDITIONS CONTRIBUTING TO CHRONIC CO-MORBIDITY OF TUBERCULOSIS: EVIDENCE FROM INDONESIAN FAMILY LIFE SURVEY 5 YEAR 2014
}

\author{
Muvida'), Vitri Widyaningsih") \\ ${ }^{1)}$ Masters Program in Public Health, Universitas Sebelas Maret \\ 2)Department of Public Health, Faculty of Medicine, Universitas Sebelas Maret
}

\begin{abstract}
Background: Tuberculosis (TB) and HIV/AIDS persist as global emergencies. Noncommunicable diseases interact adversely with TB by increasing both individual vulnerabilities to disease and the likelihood that the epidemic will be sustained within a population. Individual vulnerability is affected by the number and severity of co-morbid disorders. This study aimed to estimate the likelihood of some conditions to contribute to the chronic co-morbidity of TB.

Subjects and Method: This was a cross sectional study. A sample of 31,185 study subjects aged $\geq 18$ years old with TB was selected for this study. The dependent variable was chronic co-morbidity. The independent variables were chronic pulmonary disease, asthma, diabetes, and hypertension. The data were obtained from Indonesian family life survey 5 (IFLS 5) year 2014. The data were analyzed by a multiple logistic regression run on Stata 13.

Results: The three highest contributors of chronic co-morbidity in TB patients were: (1) hypertension (19.1\%), (2) chronic pulmonary disease (14.9\%), and (3) asthma (13.7\%). The lowest contributors of chronic co-morbidity were: (1) stroke (1.0\%) and (2) hyperlipidemia (6.0\%). The risk of chronic co-morbidity in TB patient increased with chronic pulmonary disease $(\mathrm{OR}=8.21 ; 95 \% \mathrm{CI}=5.52$ to $12.21 ; \mathrm{p}<0.001)$, asthma $(\mathrm{OR}=$ 5.64; $95 \% \mathrm{CI}=3.86$ to $8.25 ; \mathrm{p}<0.001)$, diabetes $(\mathrm{OR}=5.49 ; 95 \% \mathrm{CI}=2.27$ to 13.26 ; $\mathrm{p}<0.001)$, and hypertension ( $\mathrm{OR}=2.12$; $95 \% \mathrm{CI}=1.11$ to 4.04 ; $\mathrm{p}=0.023)$.

Conclusion: The three highest contributors of chronic co-morbidity in TB patients are: (1) hypertension, (2) chronic pulmonary disease, and (3) asthma. The lowest contributors of chronic co-morbidity were: (1) stroke and (2) hyperlipidemia. The risk of chronic co-morbidity in TB patient increases with chronic pulmonary disease, asthma, diabetes, and hypertension.
\end{abstract}

Keywords: tuberculosis, co-morbidity, chronic pulmonary disease, asthma, diabetes

\section{Correspondence:}

Muvida. Masters Program in Public Health, Universitas Sebelas Maret. Jl. Ir. Sutami 36A, Surakarta 57126, Central java, Indonesia. Email: muvidamd@gmail.com. Mobile: +6289651450435 . 